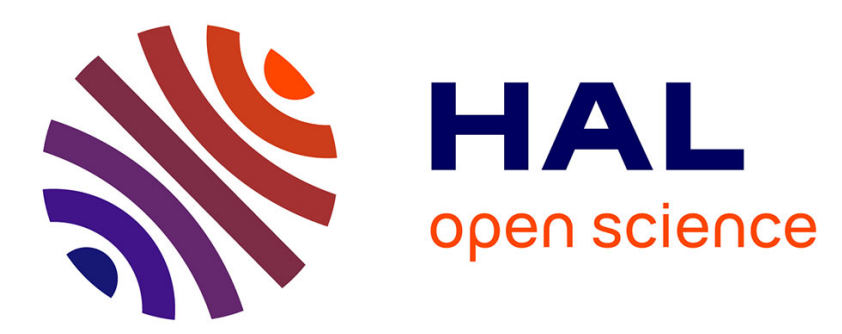

\title{
Generic and SME-specific factors that influence the BIM adoption process: an overview that highlights gaps in the literature
}

Elodie Hochscheid, Gilles Halin

\section{- To cite this version:}

Elodie Hochscheid, Gilles Halin. Generic and SME-specific factors that influence the BIM adoption process: an overview that highlights gaps in the literature. Frontiers of Engineering Management, 2020, 7 (1), pp.119-130. 10.1007/s42524-019-0043-2 . hal-02558364

\section{HAL Id: hal-02558364 \\ https://hal.science/hal-02558364}

Submitted on 18 Jun 2020

HAL is a multi-disciplinary open access archive for the deposit and dissemination of scientific research documents, whether they are published or not. The documents may come from teaching and research institutions in France or abroad, or from public or private research centers.
L'archive ouverte pluridisciplinaire HAL, est destinée au dépôt et à la diffusion de documents scientifiques de niveau recherche, publiés ou non, émanant des établissements d'enseignement et de recherche français ou étrangers, des laboratoires publics ou privés. 


\section{Generic and SME-specific factors that influence the BIM adoption process: an overview that highlights gaps in the literature}

\begin{abstract}
Building information modeling/management (BIM) is an emerging technological and procedural shift in the architecture, engineering, construction and operation industry. In this study, we use an extensive state-of-the-art method to clarify the BIM adoption process and the factors that can influence the success or failure of BIM adoption, particularly during the implementation stage, which are not frequently found in the literature. As an innovation, the lexical field allocated to the spread of innovations is assigned to BIM (diffusion, adoption, and implementation). After recalling the definition of relevant terms and then removing the resulting inconsistencies in vocabularies, we investigate various studies to identify factors that influence BIM adoption and then unify all these studies in one coherent and consistent BIM adoption process model. We focus on factors that play a role in the adoption of BIM in small- and medium-sized enterprises (SMEs) because SMEs constitute the majority of companies in the construction sector. This research highlights and intends to fill in some gaps found in the current BIM adoption literature.
\end{abstract}

Keywords BIM, adoption, diffusion, implementation, change management, SMEs, literature review, architecture firms

\section{Introduction}

Building information modeling/management (BIM) is a technology, including techniques and processes, based on the utilization/exchange of a digital mock-up among construction project actors for managing the life cycle of a building. BIM is considered an emerging technological shift (Succar, 2009) in the architecture, engineering, construction and operation (AECO) industry. Connecting the BIM diffusion/adoption/implementation literature to change management, which is a domain that provides models and strategies for analyzing and implementing changes, exhibits an interesting research potential that is insufficiently investigated (Holzer, 2015). Thus, we use this approach to study BIM adoption.

The methodology used in this study was an in-depth, non-automatic literature review that made the construction of an overview of factors that can influence BIM adoption possible. However, one of our previous work (Hochscheid and Halin, 2018a) and a complete definition of BIM adoption vocabulary (adoption, diffusion, implementation) pointed out recurring gaps in major papers in this literature, along with the lack of an overall vision of the adoption process and factors that can influence it throughout the process. This study aims to highlight and fill in these gaps.

Part 2 clarifies the definitions of diffusion, adoption, and implementation. Part 3 enumerates and addresses the factors identified in the literature that play a role in the adoption and success/failure in the implementation of an innovation. Part 4 focuses on how small- and mediumsized enterprises (SMEs) deal with BIM/innovation adoption. Part 5 highlights the gaps in the literature and proposes a unified synthesis of factors that may influence BIM adoption and integrate these factors into a BIM adoption process model (Rogers, 2003). 


\section{Diffusion, adoption, and implementation}

BIM is considered an innovation. The lexical field that is generally attributed to the spread of innovations is also ascribed to BIM (e.g., diffusion, adoption, and implementation). However, the definitions of these terms are not always explicit in the BIM-specific literature and they convey different meanings.

Diffusion is "a concept that represents the spread of the system/process within a population of adopters" (Kassem and Succar, 2017). "The diffusion process is characterized by increases over time in both the number of firms using or owning a technology (inter-firm diffusion) and more intensive use of the technology by the firm (intra-firm diffusion)" (Stoneman and Diederen, 1994).

Implementation is "a set of activities undertaken to prepare for, deploy, or improve specific deliverables and their related workflows" (Kassem and Succar, 2017).

Adoption has the vaguest definition. It can refer to:

- a decision taken by a company's management to start integrating a technology (Klein and Sorra, 1996; Ahmed et al., 2017). It is also described as a final stage in a decision-making process (Hosseini et al., 2018); that is, it culminates in a resolution to adopt and use a new system.

- the moment actors have achieved a certain level of mastery of a technology after a preparation period (called point of adoption or PoA by Succar and Kassem (2015)).

- a process that includes implementation (Rogers, 2003); that is, adoption is a combination of implementation and diffusion concepts (Succar and Kassem, 2015).

In 1963, Everett Rogers published the first version of a famous research on innovation: Diffusion of Innovations (Rogers, 2003). He described the innovation-decision process based on five stages (Table 1). This model has been adopted, renamed, became the model of the adoption process (Karlsson, 1988) (Table 1), and recently readopted in the BIM-specific literature (Ahmed et al., 2017) (Table 1), where decision (at Stage 3) became the PoA.

However, considering adoption as a decision is not new: "innovation implementation presupposes innovation adoption, that is, a decision, typically made by senior organizational managers that the employees within the organization will use the innovation in their work" (Klein and Sorra, 1996). This definition is also used in the information technology adoption literature for technology acceptance models (TAMs): "TAM2 reflects the impacts of (...) forces impinging on an individual facing the opportunity to adopt or reject a new system" (Venkatesh and Davis, 2000). This definition exhibits continuity with Rogers's model, in which Stage 3 can lead to adoption or rejection and Stage 5 is the continued (or effective) adoption or rejection. In the BIM-specific literature, Succar and Kassem (2015) described BIM adoption as "a single construct combining the concepts of implementation and diffusion."

Given that we focus on the process that companies go through to use BIM, we must establish a clear demarcation among the decision of adoption (DoA), effective implementation (EI), and the moment technology has been effectively adopted or the confirmation of adoption (CoA), as shown in Fig. 3 in Part 5 (Hochscheid and Halin, 2018b).

\section{Factors that influence BIM adoption}

Innovation adoption is a long and complex process that includes implementation (Hochscheid and Halin, 2018b). In this section, we provide an overview of factors that may influence the BIM adoption process by exploring various research areas.

\subsection{BIM implementation is a risky operation for a firm}

The BIM literature has focused on the adoption level (particularly comparative analysis) and the benefits associated with implementation (Arayici et al., 2011; McGraw Hill Construction, 2014; Smith, 2014; Bonanomi et al., 2016; Kassem and Succar, 2017). However, any operation that generates benefits is also likely to produce negative effects (Al-Bahar and Crandall, 1990). Digital transition and change are risky operations for a company.

A risk event is "what might happen to the detriment or in favor of the project" (Al-Bahar and Crandall, 1990). All risk events do not have the same chance of occurrence. This phenomenon is called uncertainty of an event (Al-Bahar and Crandall, 1990). Risk management consists of identifying and analyzing risks and formulating a response to anticipate their occurrence (Al-Bahar and Crandall, 1990; Chien et al., 2014 ; Bonanomi et al., 2016). Some studies have focused on risks for BIM projects (Chien et al., 2014). However, only a few studies have focused on recurring risks (e.g., organization death and returning to previous practices) and risk factors (e.g., what increases the likelihood for risks to occur) related to digital transition in design firms.

Table 1 Different models in five stages that describe the innovation adoption/decision process

\begin{tabular}{cccccc}
\hline Stage 1 & Stage 2 & Stage 3 & Stage 4 & Stage 5 & Reference \\
\hline Knowledge & Persuasion & Decision & Implementation & Confirmation & Rogers, 2003 \\
Awareness & Interest & Trial & Evaluation & Adoption & Karlsson, 1988 \\
Awareness & Intention and interest & PoA & Implementation & Confirmation & Ahmed et al., 2017 \\
\hline
\end{tabular}


Bonanomi et al. (2016) identified two types of risk factors for implementation, namely, endogenous (coming from an internal context of the firm) and exogenous (coming from an external context of the firm) risks. Social, managerial, technical, economical, and institutional risks linked to BIM implementation in design firms are identified in the literature (Chien et al., 2014; Bonanomi et al., 2016). We propose to link these risk factors to the generic literature on innovation adoption and change management to differentiate adoption decision factors (DFs) and implementation factors (IFs).

BIM implementation is a risky operation for firms (Hochscheid and Halin, 2018a). In this study, we identify recurring adoption and implementation risks and risk factors for fast identification and to prevent implementation failure in firms.

\subsection{Innovation adoption factors}

Many studies on factors that influence the decision to adopt $\mathrm{BIM} /$ innovation are available and have originated from various fields. Sociological psychology has been investigated to understand the psychological and social aspects involved in the DoA of an innovation. These models and theories primarily focus on the perception of a user on a technology, which determines its ease of use and usefulness. This perception is partially determined by the profile and characteristics of the user. The best known theory for this perception is TAM, which was proposed by Davis (1989) and updated with Venkatesh and Davis (2000). A state-of-the-art representative of these models can be found in Tétard and Collan (2009).

Economy, sociology, and strategic management have been investigated on the basis of institutional theory (DiMaggio and Powell, 2000), which describes institutional pressures that motivate organizations to implement change: coercive isomorphism (responding to cultural expectations), mimetic processes (facing uncertainties), and normative pressures (undergoing standardization of training and procedures).

A summary of factors that affect innovation adoption from various literature can be found in Waarts et al. (2002) (innovation generic), as cited by Ahmed et al. (2017) (BIM-specific).

- Perceived BIM/innovation characteristics:

A firm's idea of the value of an innovation (Waarts et al., 2002) as the perceived usefulness of a technology and perceived ease of use (Davis, 1989), relative advantage, compatibility, complexity, trialability, observability, and technological factors (Rogers, 2003).

- Adopter/internal environment characteristics:

This factor appears in Waarts et al. (2002) and is integrated into "internal environment" in Ahmed et al. (2017).

It refers to a company's general attitude toward the innovation type and financial resources that it devotes to IT technologies. This factor includes top management support, communication behavior, financial resources, organizational readiness, social motivations, organization culture, willingness/intention, and organization size.

\section{- External environment characteristics:}

Coercive pressures, mimetic pressures, normative pressures, market forces, and supply chain integration.

This literature is useful in understanding why an enterprise or an individual chooses to adopt a technology. Factors that facilitate DoA are called adoption decision drivers. However, these factors intervene before the decision to adopt (Stage 3 in Rogers's model). Thus, they do not help understand what causes an adoption to fail after DoA has been made.

3.3 Are there firms that are unable to adopt an innovation, such as BIM?

If the adopter's characteristics play a role in the success of the adoption process (Section 3.2), then we may ask whether some firms cannot integrate BIM because of their specific internal characteristics. In this section, we identify the risk factors and risks for firms related to the BIM adoption process.

\subsubsection{Population ecology theory}

A large proportion of the organizational, management, and sociological literature subscribes to the adaptation perspective (Singh et al., 1986). In this perspective, leaders or top managers observe the environment of the organization to detect opportunities and threats and then formulate strategic responses to appropriately adjust the organizational structure. Therefore, changes are made to reduce organizational death rates.

The adaptation perspective was challenged in the 1970s by population ecology theory (Hannan and Freeman, 1977; Singh et al., 1986; Aldrich, 2008), which argues that organizations have high levels of structural inertia that make organizational adaptation difficult, and sometimes, even impossible. A major argument of population ecology theory is that organizations rarely make major adaptive changes (i.e., organizational changes are frequently considered disruptive) and that the ability of organizations to adapt has numerous limitations (Hannan and Freeman, 1977). Two types of limitations are mentioned:

\section{- Inertial pressures}

Limitations that come from the company itself: 1 - previous choices made (equipment and specialized personnel), 2-the type of information that decision makers receive, 3 -internal political constraints, and 4 - history of the firm (Hannan and Freeman, 1977). These limitations imply that not all companies are equal in the face of change. 


\section{- External pressures}

These limitations include: 5-legal and fiscal barriers, 6-information dissemination channels, 7-legitimacy constraints, and 8 -collective rationality problem (Hannan and Freeman, 1977).

Not all companies are equal when facing change. This concept is interesting from the perspective of massive BIM adoption. How can BIM be implemented? What are its consequences on the AECO industry?

In the models of Rogers (2003) and Ahmed et al. (2017), only the rejection decision can stop the adoption process (Stage 3, Table 1). Hannan and Freeman (1984) described the pressures that can lead to the failure of implementation or reorganization, the different steps where implementation can stop, and the form that this failure can take. An organization may die because it has not adapted quickly enough $(d)$. If a structure decides to reorganize $(a)$, then the operation can lead to success $(c)$, death $(e)$, or return to previous practices $(b)$. Moreover, the new configuration may not be adapted to environment, and the organization can die (f) (Hannan and Freeman, 1984; Hochscheid and Halin, 2018b).

In population ecology theory, "population" refers to aggregates of organizations rather than individuals (Hannan and Freeman, 1977). The adaptation of organizational structure to environments principally occurs at the population level (Hannan and Freeman, 1984). In this view, organizations that fit the environment survive, whereas those that are unable to adapt rapidly die.

The manner in which the identified factors influence firms' mortality has been the subject of hypotheses (called assumptions in Hannan and Freeman (1984)). They concern the characteristics of a company (i.e., size, agespecialized, or generalist), external environment (i.e., stable, uncertain), and the implementation method for change (i.e., type, speed) (Hannan and Freeman, 1977). Some of these hypotheses have been tested, and the empirical study of these factors does not show a clear impact of these characteristics on the mortality of an organization and fails to exhibit the predictive capacity of this theory (Singh et al., 1986). However, these factors remain interesting because they have not been investigated in the case of BIM adoption. Moreover, studying organizations as populations can help identify the general trends in the BIM field.

\subsubsection{Specific case of architecture firms}

In a previous research (Hochscheid and Halin, 2018a), we conducted interviews and action research on the specific case of BIM implementation for French architecture firms. This research demonstrated the influence of (1) some characteristics of the company and (2) certain implementation method for change on the success or failure of BIM implementation. For example, firms that have not integrated resource pooling, process standardization, and pyramidal hierarchy within the company experience difficulties in BIM implementation. The types of projects and partners also play a role in the ability of firms to implement BIM. This study is the first step in identifying risk factors that may lead to implementation failure using qualitative research methods.

Most studies on the factors that influence BIM in SMEs do not differentiate among engineering, architecture, and other firms and regard "SMEs in the construction sector" in a generic manner. However, if the adoption process depends on the internal characteristics of a firm, then this lack of differentiation can create a gap in the literature.

\subsection{Change management}

During the 1980s and 1990s, the software development paradigm (when each company develops its own tools, adapts to its practice) gave way to the software edition paradigm (publisher market software on a large scale for the greatest number). This changeover is at the origin of the highly pragmatic managerial questions linked to the support of companies in the integration of information technologies (Autissier et al., 2014). Change management is a domain that provides theoretical/practical models and strategies to analyze and implement change (Holzer, 2015). This discipline is focused on the implementation part of adoption and can be interesting in the investigation of BIM implementation.

We summarized elements that are identified in this literature as factors that impact adoption based on state-ofthe-art change management (Autissier et al., 2014). These elements are classified into two categories: the characteristics of the company context (Table 2) and change characteristics (Table 3).

The elements in Table 2 are highly similar to those found in population ecology theory (e.g., inertial and external pressures). However, the external context is included in "the context of the firm" and not detailed because change management focuses on the firm itself. In institutional theory (DiMaggio and Powell, 2000), this external context is dissected in coercive isomorphism, mimetic processes, and normative pressures.

The factors summarized in Table 3 have been the subject of empirical studies and action research. Their involvement in the success/failure of implementation has been demonstrated, but AEC-specific examples are rare. Lines et al. (2015) attempted to determine what causes resistance to change in the implementation of new processes in AEC firms (resistance to change can lead to adoption failure). They proposed hypotheses based on organization characteristics (project: scope, size, and duration; people: position level and career stage) and change characteristics (organizational expectations: implementation speed and organizational shift; implementation method: change message received, presence of formal agents, and involve- 
Table 2 Characteristics of the company context in the change management field

\begin{tabular}{lclcc}
\hline Level & Context & & Description & Reference \\
\hline L3 & External context & Social, economic, competitive, and political environment & (a); (b) \\
L2 & Culture & Vision, principles, beliefs, values, projects (products), strategies & (a)-(e) & (a)-(e) \\
& Interactions & Hierarchy, division of power, distribution of work and responsibilities, collaboration & (b); (c); (e) & (c); (e) \\
& Systems & Software, hardware, processes & \\
L1 & People & People, experience, seniority, career stage, skills &
\end{tabular}

Note: L3, the global level; L2, the organizational level; L1, the personal level. (a) Greenwood and Hinings, 1988; (b) Pettigrew, 1987; (c) Sainsaulieu and Segrestin, 1986; (d) Burgelman and Mittman, 1994; (e) Mintzberg and Westley, 1992.

Table 3 Change characteristics that have been identified in the literature to play a role in the success of change (adapted from Autissier et al., 2014)

\begin{tabular}{|c|c|c|c|}
\hline Characteristics & Context & Description & Reference \\
\hline \multirow[t]{2}{*}{ Extent } & Global & $\begin{array}{l}\text { Change affects all activities and units of the organization. The company's strategy and culture } \\
\text { evolve }\end{array}$ & (f) \\
\hline & Partial & $\begin{array}{l}\text { Change affects a portion of the organization, thereby preserving the previous strategy, culture, and } \\
\text { structure. Modifying the company's performance is frequently insufficient }\end{array}$ & (f) \\
\hline \multirow[t]{2}{*}{ Depth } & Disruptive & $\begin{array}{l}\text { Disruptive change marks a considerable difference with the past with clear discontinuity. It changes } \\
\text { strategy, process, and organizational culture and affects the company's performance }\end{array}$ & (f); (g) \\
\hline & Adaptative & $\begin{array}{l}\text { Adaptive change is a modification of the actual situation. It lightly evolves the content, process, and } \\
\text { missions of the organization }\end{array}$ & (f); (g) \\
\hline \multirow[t]{2}{*}{ Rhythm } & Fast & $\begin{array}{l}\text { Fast change is a redress and a resolution against a past situation, but extremely rapid change can } \\
\text { place the organization at risk }\end{array}$ & (h) \\
\hline & Slow & $\begin{array}{l}\text { Slow change consists of a gradual approach to ensure a new balance thereafter. Slow change can } \\
\text { lead to getting used to an undesirable situation }\end{array}$ & (h) \\
\hline \multirow[t]{2}{*}{ Base } & Imposed & $\begin{array}{l}\text { Imposed change is a change in which management acts decisively and where opportunities for } \\
\text { negotiation are minimal }\end{array}$ & (f) \\
\hline & Negotiated & $\begin{array}{l}\text { Managers are caught between limiting resistance to change and respond to customer demands. } \\
\text { Convinced that imposed change has minimal chance of success, they integrate teams to limit } \\
\text { resistance. Placing the cursor between firmness and negotiation is difficult }\end{array}$ & (f) \\
\hline
\end{tabular}

Note: (f) Autissier et al., 2014; (g) Hannan and Freeman, 1984; (h) Kotter and Cohen, 2002.

ment of change agents). They demonstrated that nearly all these hypotheses, except for "expected organization shift", are strongly correlated with resistance to change. This type of BIM-specific studies is extremely rare, and some of the aforementioned factors are difficult to measure or identify in firms.

\section{BIM adoption among SMEs}

The diffusion of innovations is slow in the construction sector partly because it is composed largely of SMEs (Turk, 2000). Therefore, identifying the specificities of SMEs in the case of technology adoption is interesting.

\subsection{SMEs are key players}

SMEs are the key players in the construction sector in most countries. However, numerous studies have pointed out that minimal information is available with regard to how BIM is implemented in SMEs. Most of these studies have focused on the construction sector in the UK (Abuelmaatti et al., 2014; Bataw et al., 2014; Kouider and Paterson, 2014; Ghaffarianhoseini et al., 2016; Machado et al., 2016) or in Australia (Hong et al., 2016; Hosseini et al., 2016) probably due to early legislations related to BIM in these countries.

An enterprise can be considered an SME when it has less than 250 employees. However, when it comes to implementing an innovation, companies with 150 or 200 employees do not have the same constraints as those with only 5 or 15 employees, even though all of these companies are classified as SMEs.

In France, 99.9\% of enterprises in this sector are SMEs, including $96.1 \%$ of micro-enterprises (A, Fig. 1). The proportion of intermediate-sized and large enterprises in this sector is quasi-negligible. BIM potentialities are mostly demonstrated in extremely large projects imple- 
mented by large enterprises, which represent only a very small minority of enterprises in this sector.

Nevertheless, large companies represent a very important workforce. The distribution of the number of employees in the sector (B, Fig. 1) shows that $30 \%$ of the employees in this sector work in intermediate-sized and large enterprises. Micro-enterprises represent $34 \%$ of the number of employees in the construction sector, which is not negligible.

A large part of the research on BIM implementation in SMEs remains at the level of the construction sector, which is extremely heterogeneous (in terms of specializations and interest in using BIM). We propose to focus on a profession, i.e., architects. BIM can only be used in an optimized manner if all the actors in the chain are involved. However, architects are at the heart of the process and are nearly always at the origin of the first model of a project.

In France, 93\% of architecture firms that employ at least 1 person are micro enterprises (C, Fig. 2) , and $76 \%$ of micro enterprises employ less than 5 people. With the exception of self-employed architects, $85 \%$ of architects work in companies that employ less than 20 people. In France, only 1 architecture firm is beyond the SME status based on the annual ranking of architecture firms (Caille, 2017) and the official definition of SMEs (Hosseini et al., 2018). The majority of full-time equivalent salaried architects in architecture firms (67\%) work in micro enterprises (D, Fig. 2).

No official statistics link the size of agencies to the type or size of a project being implemented (public procurement, private procurement). However, action research and interviews conducted among architects (Hochscheid and Halin, 2018a) show that micro enterprises work on public procurement that are affected by changes in public procurement legislation due to BIM.

The average size of firms in the construction sector is not representative of that of architecture firms, which have extremely small structures. Architects are at the heart of the BIM process because they frequently produce the first model exchange. Therefore, the question of BIM is clearly linked to the implementation of innovations in SMEs, particularly micro enterprises.

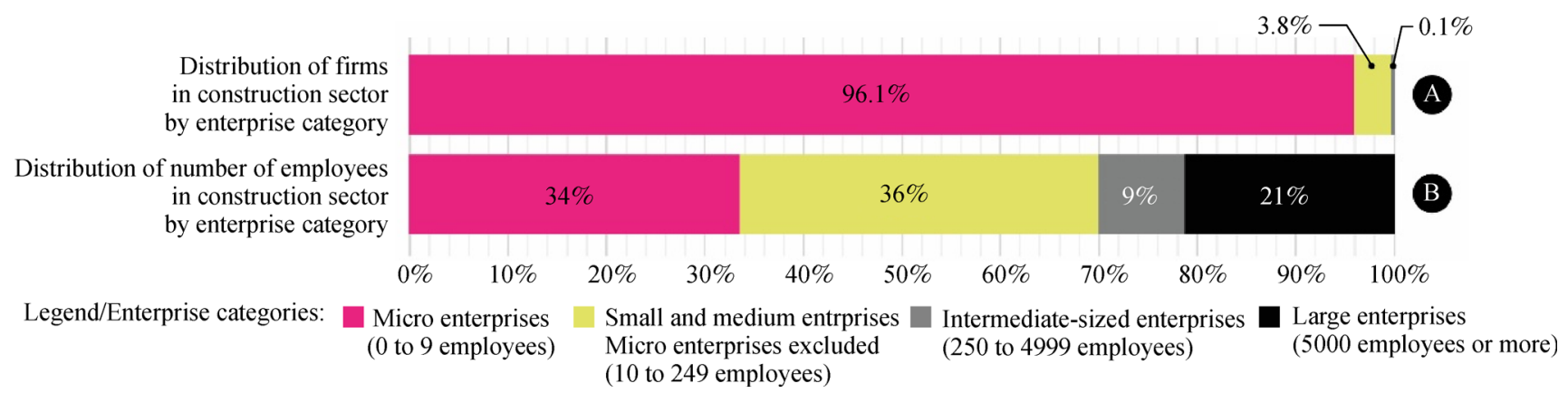

Fig. 1 State space for the distribution of firms ${ }^{1)}$ and employees in the construction sector by enterprise categories in France in 2013.

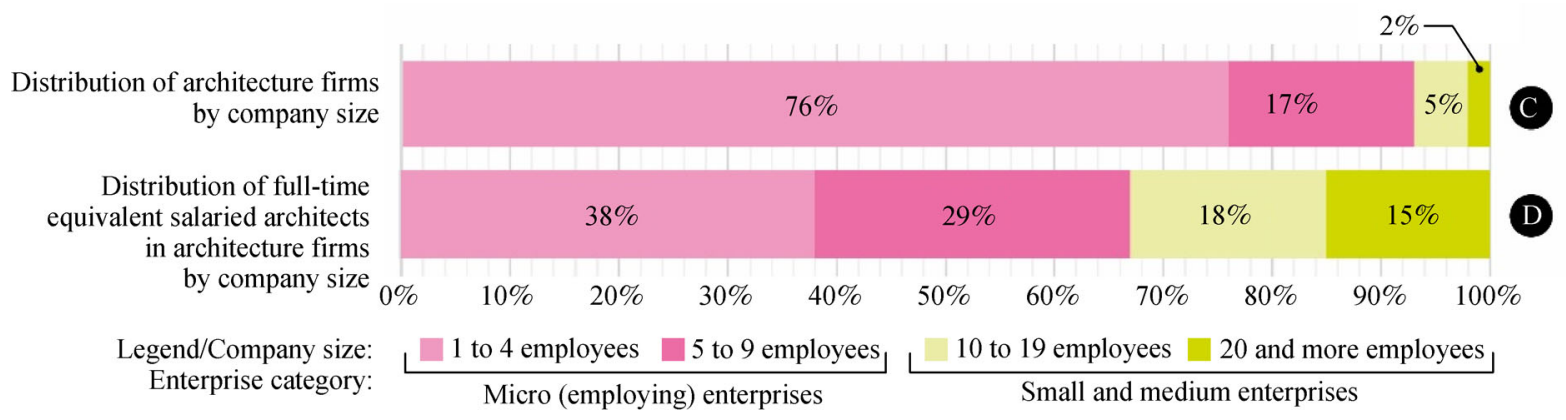

Fig. 2 Distribution of architecture firms and salaried architects in architecture firms by company size in France in 2014 (adapted from a report of the French Institute of Architects, 2016) ${ }^{2)}$

1) Definitions of micro, small, medium-sized, intermediate-sized, and large enterprises (Insee, 2016)

2) Figure 32 in this report

3) It cannot be compared with the percentage of micro enterprises in the construction sector (A, Fig. 1) because it excludes architects who work alone (enterprises without employees). We do not have access to the number of micro architecture firms, including architects working alone, in France. 
4.2 Addressing BIM adoption and implementation in SMEs and micro enterprises

During the 1980s and 1990s, the software development paradigm (when each company develops its own tools, adopts to its practice) gave way to the software edition paradigm (publisher market software on a large scale for the greatest number). The companies that used these tools had to adapt and configure their practices to the available tools, particularly small companies that cannot develop their own tools. This changeover is at the origin of highly pragmatic managerial questions and led to change management research (Autissier et al., 2014). The change management and innovation literature began to focus on SMEs around the years 1990-2000 (Edwards et al., 2005; Barba-Sánchez et al., 2007; Laforet, 2013) due to the development of information technology and the change in management research.

Many studies have focused on BIM adoption for the past 10 years from several perspectives, e.g., theoretical frameworks and conceptual models (Ahmed et al., 2017), macro adoption (Succar and Kassem, 2015), quantitative research with surveys (Malleson et al., 2016; Kassem and Succar, 2017), and barriers in BIM adoption (Gu and London, 2010; Arayici et al., 2011; Bonanomi et al., 2016). However, work that focuses on BIM implementation methods and empirical studies on SMEs is recent.

The purpose of the following state-of-the-art methods is to highlight the specificities of SMEs with regard to the implementation of innovations. The question is not about determining how companies influence one another similar to an inter-organizational diffusion pattern, e.g., coercive isomorphism, mimetic processes, and normative pressures (DiMaggio and Powell, 2000; Succar and Kassem, 2015), but to understand SME-specific implementation challenges, advantages, and disadvantages in a changing context. All enterprises face internal resistance to change (Lines et al., 2015; Ghaffarianhoseini et al., 2016) and legal barriers (Gledson et al., 2012; Bataw et al., 2014), but some aspects are specific to SMEs.

\subsubsection{Organizational advantages}

SMEs are more flexible than large enterprises (Winch and McDonald, 1999; Hong et al., 2016), and their shorter internal lines of communication allow them to reduce their response time for problem solving (Winch and McDonald, 1999). Large enterprises face significant inertia and have to deal with organizational complexity. Flat hierarchy (Laforet, 2013) in SMEs facilitates internal collaboration and information sharing. SMEs also generally have shorter term projects, which allow them to make a transition faster than large firms (Winch and McDonald, 1999; Hong et al., 2016). However, technology transfer or implementation in SMEs is commonly considered a daunting task (Ghaffarianhoseini et al., 2016).

\subsubsection{Efforts}

SMEs often report that they do not have budget or time to afford implementation (hardware, training) (Gledson et al., 2012; Bataw et al., 2014; Georgiadou, 2016; Hong et al., 2016; Hosseini et al., 2016) and frequently have misgivings about the applicability of BIM to their projects (Gledson et al., 2012). They exhibit a strong apprehension about BIM implementation and consider that the effort to be exerted is extremely high (Hosseini et al., 2016). Innovation diffusion is generally slower in SMEs than in large firms. SMEs prefer to work with well-tested technologies in an artisanal manner (Hochscheid and Halin, 2018a) and are more reluctant to taking risks (Bataw et al., 2014; Machado et al., 2016) because of their economic vulnerability.

\subsubsection{BIM expertise}

SMEs frequently express that their lack of BIM expertise is an obstacle to BIM implementation (Hong et al., 2016; Hosseini et al., 2016; Machado et al., 2016) and report the weak interest or expertise of their partner (Hosseini et al., 2016). This condition is partly due to the slow adaptation of educational/training programs (Bataw et al., 2014; Hong et al., 2016) and stresses the importance of simultaneous progress by all players in the sector. Companies need entrants with up-to-date skills or need to upskill existing workforce (Kouider and Paterson, 2014). However, SMEs, particularly micro enterprises, are rarely attractive to highly qualified and specialized employees, who are approached by larger companies that oftentimes offer better salary and career development prospects. Smaller firms also generally have more polyvalent roles, whereas large companies divide work into more specialized tasks or departments.

\subsubsection{Technical problems}

Innovations take time to be integrated into the construction sector (Turk, 2000). Each project is handled by multiple actors, and teams change with projects, thereby making the development of sustainable processes difficult. Large companies are less exposed to these changes than SMEs because they frequently control a larger proportion of the project or have higher possibilities to adapt its staff competencies over projects, thereby reducing competency

1) See Kassem and Succar (2017) for a comparative market analysis that evaluates how BIM concepts, tools, and workflows are infused into the curricula of 21 countries. 
or interoperability issues. Technology barriers, as interoperability problems, are the major barrier to BIM implementation reported by SMEs (Gledson et al., 2012; Hochscheid et al., 2016). Costs related to maintenance (servers, platforms) are also barriers to BIM implementation in SMEs.

\subsubsection{Public policy and implementation protocol}

Given that the evolution of legislation to push BIM is recent, SMEs point lack of government support and public policies (Bataw et al., 2014; Poirier et al., 2015), lack of clarity in the adoption process, and lack of procedural implementation standards (Hosseini et al., 2016). Large companies are more likely to call upon change agents to manage organizational change, whereas SMEs typically adopt the approach of learning by doing, thereby missing a strategic vision for implementation (Machado et al., 2016; Winch and McDonald, 1999).

\subsubsection{Summary}

Difficulties faced by large and small enterprises when adopting BIM vary in many aspects. Given the large proportion of SMEs in the sector, integrating SME specificities into these strategies is primal because BIM regulations are evolving and implementation strategies are the subject of recent research. Economic barriers, along with the lack of strategic planning and lack of procedural implementation standards, are frequently highlighted in BIM implementation in SMEs. However, flexibility and short-term projects are assets for change in SMEs.

In the investigated literature, factors that influence BIM adoption are specified for all SMEs in the AECO sector within differentiation in the type of firms concerned. However, we have demonstrated that a specific type of SMEs (i.e., architecture firms) is differently distributed in other firms (Section 4.1). Moreover, these studies may be too generic and should be completed by more specific studies because the internal context of a firm affects its ability to implement BIM (Sections 3.2 and 3.4).

\subsection{Conclusion of part 4: need for synthesis}

All the factors mentioned in this section are not classified on the basis of the categories presented in Section 3 (e.g., external environment characteristics, external pressures, internal context, inertial pressures, innovation characteristics, and adoption characteristics). The multitude of unconnected fields of research makes gaining a clear understanding of the factors that influence BIM adoption difficult. In the following section, we provide a unified and synthetic view of Sections 2 (adoption process), 3, and 4 (influencing factors).

\section{Synthetic view: model for understanding the BIM adoption process and the factors that influence it}

This section summarizes the factors that influence BIM adoption in a unified view and presents them in a model that exemplifies the BIM adoption process.

\subsection{Adoption process}

Innovation diffusion models and TAMs have been appropriated in the BIM-specific literature. However, diffusion, adoption, and implementation processes are insufficiently defined and described. We consider BIM adoption as a five-stage process (Fig. 3) (Hochscheid and Halin, 2018b), which begins with the awareness of the existence of this innovation (Stage 1), followed by the eventuality of the intention (Stage 2), and the decision to adopt (Stage 3) based on Rogers's model (Rogers, 2003; Ahmed et al., 2017). DoA is an important moment when the company's management begins to implement change in the company. Furthermore, it marks the beginning of the implementation process. After DoA, the firm undergoes implementation (Stage 4) and deals with highly practical problems to integrate BIM into its practices. EI occurs at the end of Stage 4; that is, when everything is put into place to begin the use of BIM. Implementation is followed by a confirmation stage (Stage 5), which refers to the gradual integration of new practices into the current practices of a firm. CoA occurs when we consider that the firm has reached a certain level of mastery of new practices and is unlikely to revert to previous practices.

The adoption process can be interrupted (adoption failures) after DoA. In Stage 4, adoption can fail in the beginning of implementation. For example, if resistance to change is strong in the company. Adoption can also fail during implementation. For example, if the company is not fast enough to implement change, returns to previous practices, or dies because of the disruption caused by change (Fig. 3). In Stage 5, adoption can fail after implementation or during the confirmation stage. For example, if the implemented technology of an organization is ineffective in practice, and thus, is abandoned, or if a company dies or returns to previous practices.

\subsection{Factors that influence the BIM adoption process: a} synthesis

The adoption process in the literature is vague (Section 2). This confusion has caused a non-demarcation among the factors that influence the process (Fig. 3):

- before DoA: DFs,

- after DoA: IFs.

1) This figure is based on the "conceptual model for investigating BIM adoption decisions" proposed by Ahmed et al. (2017). We do not use the term "conceptual model" to avoid confusion with "conceptual models" used in information systems to designate a representation of a system. 
Our literature review indicates that all the factors can be classified into four categories, namely, internal context, external context, innovation characteristics, and change characteristics, by considering several terms that refer to the same concepts (Table 4).

Table 4 allows us to identify factors that play a role in BIM adoption before and after DoA. DFs are related to the internal and external contexts of a firm and the characteristics of the adopted innovation. In addition to the aforementioned factors, IFs are related to change characteristics (i.e., the manner in which change is implemented in a firm). IFs are under-investigated in the case of BIM, but recent research has taken an in-depth look at this topic (Hong et al., 2016; Murguia et al., 2017) and many surveys have been conducted on BIM adoption (PTNB, 2017; McGraw Hill Construction, 2010; McGraw Hill
Construction, 2014; Malleson et al., 2016; Waterhouse et al., 2017). A recent research on DFs (Ahmed and Kassem, 2018) is comprehensive but do not include either the implementation or confirmation stages of the adoption process.

\section{Conclusions}

Elemental distinctions among diffusion, adoption, and implementation are vague in nearly all the literature on BIM adoption. This confusion has created gaps in our understanding of the adoption process of BIM and the factors that influence it. Under-investigated research areas show that the adoption process can fail at many stages. However, current models suggest that the adoption process

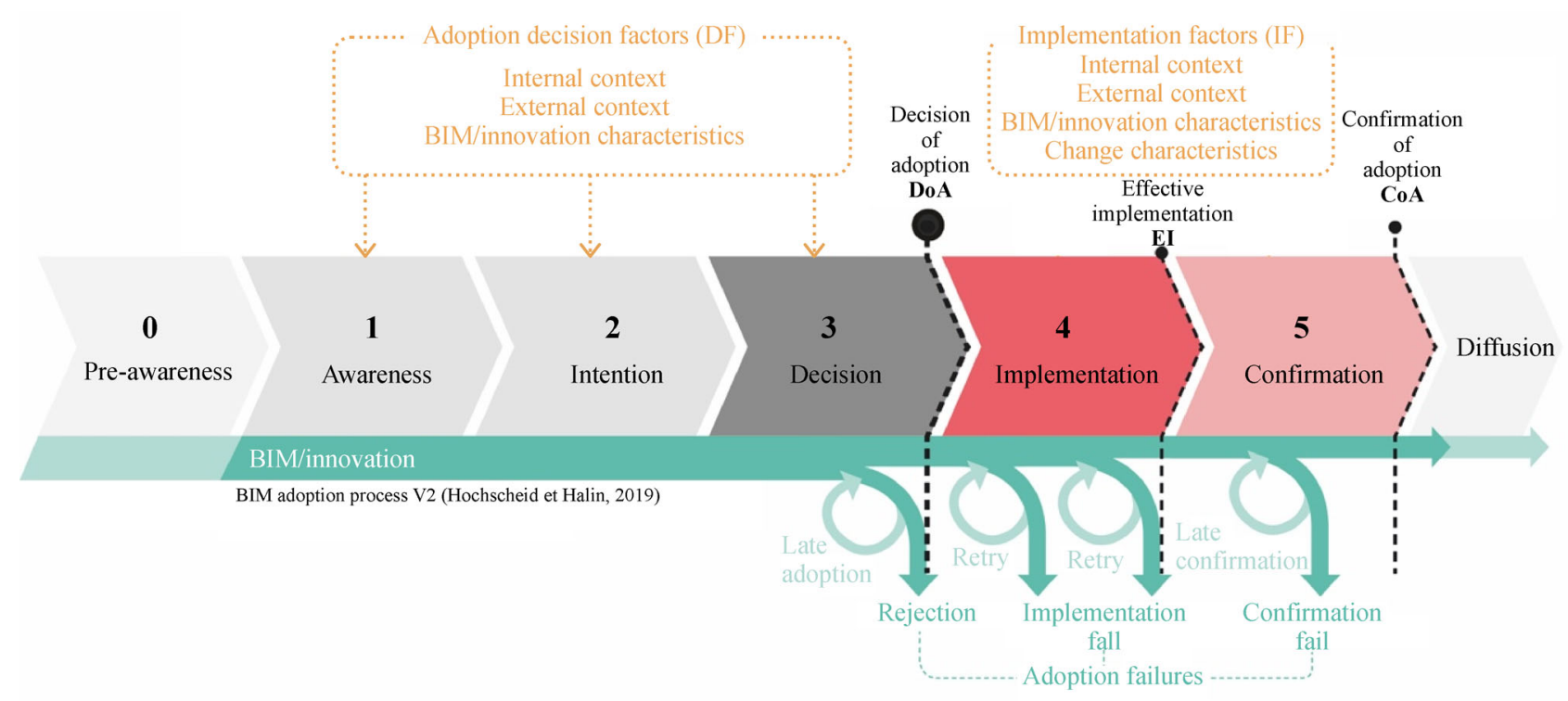

Fig. 3 Model of the BIM adoption process, with possible adoption failures and influencing factors. V2 (adapted from Rogers (2003) and Ahmed et al. (2017)) $)^{1)}$, V1 available in Hochscheid and Halin (2018b).

Table 4 Synthesis of factors that influence BIM adoption mentioned in the literature investigated in this study

\begin{tabular}{|c|c|c|c|c|c|}
\hline & Risk management & $\begin{array}{l}\text { Sociology, psychology, } \\
\text { management }\end{array}$ & Institutional theory & $\begin{array}{c}\text { Population ecology } \\
\text { theory }\end{array}$ & Change management \\
\hline Section & Section 3.1 & Section 3.2 & Section 3.2 & Section 3.3 & Section 3.4 \\
\hline Internal context & Endogenous risk & $\begin{array}{c}\text { Adopter or internal context char- } \\
\text { acteristics }\end{array}$ & $\mathrm{x}$ & Inertial pressures & L1 and L2 in Table 2 \\
\hline External context & Exogenous risk & $\begin{array}{l}\text { External environment character- } \\
\text { istics }\end{array}$ & $\begin{array}{l}\text { Coercive, mimetic, } \\
\text { normative pressures }\end{array}$ & External pressures & L3 in Table 2 \\
\hline Innovation characteristics & Exogenous risk & $\begin{array}{l}\text { Perceived innovation characteris- } \\
\text { tics }\end{array}$ & $\mathrm{x}$ & $\mathrm{x}$ & $\mathrm{x}$ \\
\hline Change characteristics & $\mathrm{x}$ & $\mathrm{x}$ & $\mathrm{x}$ & Implementation method & Table 3 \\
\hline Type of factor & $\mathrm{DF}+\mathrm{IF}$ & DF & DF & $\mathrm{DF}+\mathrm{IF}$ & IF \\
\hline
\end{tabular}


can only "fail" during the decision stage, thereby indicating that BIM is only "not adopted" when people decide to reject it. This gap occurs inter alia because of the confusion between adoption and DoA. For the same reason, studies that focus on factors that influence BIM adoption only concentrated on factors that influence DoA, thereby omitting factors that can lead to the failure of implementation or confirmation. In this study, we distinguish DFs and IFs, thereby allowing us to grasp a good understanding of the adoption process.

We show the importance of studying the case of SMEs, which are key players in the construction sector in many countries. SMEs have specific advantages and disadvantages in a changing context. However, a recent research (Hosseini et al., 2018) shows that "there is no meaningful association between BIM implementation maturity within SMEs and their organizational attributes, such as size and level of experience." Studies that focus on BIM adoption in SMEs may still be too generic and can now focus on specific firms (e.g., architecture and engineering firms).

Quantitative studies on factors that influence BIM adoption are multiplying. However, the motivation to adopt innovation changes with the number of firms in the industry that have successfully implemented this innovation. In the beginning of the inter-firm diffusion process, adopters have focused on the strategic importance of the innovation for an organization and on external forces, such as the parent company and industrial competitiveness. Thereafter, adopters tend to focus on practical implementation issues and budget (Waarts et al., 2002). Any research that aims to rank BIM adoption factors in the order with the most to the least impact will only provide a snapshot of the diffusion process at a given time. Although these studies are useful, we have to consider the aforementioned factors.

\section{References}

Abuelmaatti A A, Ahmed V S, Baban H S (2014). Collaborative technologies for small and medium-sized architecture, engineering and construction enterprises: implementation survey. Journal of Information Technology in Construction, 19: 210-224

Ahmed A L, Kassem M (2018). A unified BIM adoption taxonomy: conceptual development, empirical validation and application. Automation in Construction, 96: 103-127

Ahmed A, Kawalek P, Kassem M (2017). A conceptual model for investigating BIM adoption by organisations. In: Proceedings of the Joint Conference on Computing in Construction (JC3), Heraklion, Greece, 447-455

Al-Bahar J F, Crandall K C (1990). Systematic risk management approach for construction projects. Journal of Construction Engineering and Management, 116(3): 533-546

Aldrich H (2008). Organizations and Environments. Palo Alto, California: Stanford University Press

Arayici Y, Coates P, Koskela L, Kagioglou M, Usher C, O'reilly K
(2011). Technology adoption in the BIM implementation for lean architectural practice. Automation in Construction, 20(2): 189-195

Autissier D, Vandangeon-Derumez I, Vas A (2014). Change management, key concepts: 50 years of research from major authors. Paris: Dunod (in French)

Barba-Sánchez V, Martínez-Ruiz M, Jiménez-Zarco A I (2007). Drivers, benefits and challenges of ICT adoption by small and medium sized enterprises (SMEs): a literature review. Problems and Perspectives in Management, 5(1): 103-114

Bataw A, Burrows M, Kirkham R (2014). The challenges of adopting Building Information Modelling (BIM) principles within Small to Medium sized Enterprises (SMEs). In: Proceedings of the 14th International Conference on Construction Applications of Virtual Reality (CONVR2014), Sharjah, UAE., CONVR, 318-324

Bonanomi M, Paganin G, Talamo C (2016). BIM implementation in design firms. Risk-Response Strategies to Support Change Management, 1-9

Burgelman R A, Mittman B S (1994). An intraorganizational ecological perspective on managerial risk behavior, performance, and survival: individual, organizational and environmental effects. In: Baum J, Singh J, eds. Evolutionary Dynamics in Organizations. New York: Oxford University Press

Caille E (2017). Ranking of the first 300 architecture firms in France by sales revenue. D'Architectures, 166-180 (in French)

Chien K F, Wu Z H, Huang S C (2014). Identifying and assessing critical risk factors for BIM projects: empirical study. Automation in Construction, 45: 1-15

Davis F D (1989). Perceived usefulness, perceived ease of use, and user acceptance of information technology. Management Information Systems Quarterly, 13(3): 319-340

DiMaggio P J, Powell W W (1983). The iron cage revisited: institutional isomorphism and collective rationality in organizational fields. American Sociologiview, 48(2):147-160

Edwards T, Delbridge R, Munday M (2005). Understanding innovation in small and medium-sized enterprises: a process manifest. Technovation, 25(10): 1119-1127

Georgiadou M C (2016). Building Information Modelling in UK construction projects: a state of the art review. In: COBRA 2016, Toronto, Canada

Ghaffarianhoseini A, Doan D T, Zhang T, Ghaffarianhoseini A, Naismith N, Tookey J (2016). A BIM readiness \& implementation strategy for SME construction companies in the UK. In: Proceedings of the 33rd CIB W78 Conference

Gledson B, Henry D, Bleanch P (2012). Does size matter? Experiences and perspectives of BIM implementation from large and SME construction contractors In: 1st UK Academic Conference on Building Information Management (BIM) 2012, Northumbria University, Newcastle upon Tyne, UK

Greenwood R, Hinings C R (1988). Organizational design types, tracks and the dynamics of strategic change. Organization Studies, 9(3): 293-316

Gu N, London K (2010). Understanding and facilitating BIM adoption in the AEC industry. Automation in Construction, 19(8): 988-999

Hannan M T, Freeman J (1977). The population ecology of organizations. American Journal of Sociology , 82(5): 929-964 
Hannan M T, Freeman J (1984). Structural inertia and organizational change. A merican Sociological Review , 49(2): 149-164

Hochscheid E, Halin G (2018a). BIM implementation in architecture firms: interviews, case studies and action research used to build a method that facilitates implementation of BIM processes and tools. In: Proceedings of the 36th ECAADe Annual Conference, Lodz, Poland, 10

Hochscheid E, Halin G (2018b). A model to approach BIM adoption process and possible BIM implementation failures. In: Proceedings of the Creative Construction Conference 2018 (CCC), Ljubljana, Slovenia

Hochscheid E, Ribereau-Gayon M, Halin G, Hanser D (2016). BIM implementation in SMEs: an experience of cooperation between an architect agency and a carpentry firm. In: Proceedings of ICCCBE2016, Osaka, Japan

Holzer D (2015). The BIM Manager's Handbook, Part 2: Change Management. New York: John Wiley \& Sons

Hong Y, Sepasgozar S M, Ahmadian A F F, Akbarnezhad A (2016). Factors influencing BIM adoption in small and medium sized construction organizations. In: Proceedings of the International Symposium on Automation and Robotics in Construction, Vilnius Gediminas Technical University,

Hosseini M R, Namzadi M O, Rameezdeen R, Banihashemi S, Chileshe N (2016). Barriers to BIM adoption: Perceptions from Australian small and medium-sized enterprises (SMEs). In: AUBEA 2016: Proceedings of the 40th Australasian Universities Building Education Association Annual Conference, Central Queensland University, 271-280

Hosseini R, Pärn E, Edwards D, Papadonikolaki E, Oraee M (2018) Roadmap to mature BIM use in Australian SMEs: competitive dynamics perspective. Journal of Management Engineering, 34(5): 05018008

Insee (2015). The national institute of statistics and economic studies collects, analyses and disseminates information on the French economy and society, Construction sector-Companies in France. Insee References (in French), free access in Insee website

Insee (2016). The national institute of statistics and economic studies collects, Decree n²008-1354 article 3. Definition of Enterprise Categories (in French), free access in Insee website

Insee (2017). The national institute of statistics and economic studies collects, analyses and disseminates information on the French economy and society, economic outlook. Insee References (in French), free access in Insee website

Karlsson C (1988). Innovation adoption and the product life cycle. Dissertation for the Doctoral Degree. Umeå: Umeå a Universitet

Kassem M, Succar B (2017). Macro BIM adoption: comparative market analysis. Automation in Construction, 81: 286-299

Klein K J, Sorra J S (1996). The challenge of innovation implementation. Academy of Management Review, 21(4): 1055-1080

Kotter J P, Cohen D S (2002). The Heart of Change: Real-Life Stories of How People Change Their Organizations. Boston: Harvard Business School Press

Kouider T, Paterson J J G (2014). Architectural technology and the BIM acronym: 2. Reviewing evolving paradigms for BIM implementation among SMEs. In: Architectural Technology, Towards Innovative
Professional Practice: Conference Proceedings of the 5th International Congress of Architectural Technology, Aberdeen 2014 (ICAT2014), Robert Gordon University

Laforet S (2013). Organizational innovation outcomes in SMEs: effects of age, size, and sector. Journal of World Business, 48(4): 490-502

Lines B C, Sullivan K T, Smithwick J B, Mischung J (2015). Overcoming resistance to change in engineering and construction: change management factors for owner organizations. International Journal of Project Management, 33(5): 1170-1179

Machado M, Underwood J, Fleming A J (2016). Implementing BIM to streamline a design, manufacture, and fitting workflow: a case study on a fit-out SME in the UK. International Journal of 3-D Information Modeling, 5(3): 31-46

Malleson A, Kato H, Popíšilová B, Watson D, Friborg G (2016). NBS International BIM Report 2016. NBS Report

McGraw Hill Construction (2010). The business value of BIM in Europe: getting building information modelling to the bottom line the United Kingdom, France and Germany

McGraw Hill Construction (2014). The business value of BIM for construction in major global markets: how contractors around the world are driving innovations with Building Information Modelling. Smart Mark

Mintzberg H, Westley F (1992). Cycles of organizational change. Strategic Management Journal, 13(S2): 39-59

Murguia S D E, Demian P, Soetanto R (2017). A systemic BIM innovation model in the construction supply chain. In: Proceedings of the 33rd Annual ARCOM Conference, Cambridge, UK 15-24

Pettigrew A M (1987). Context and action in the transformation of the firm. Journal of Management Studies, 24(6): 649-670

Poirier E, Staub-French S, Forgues D (2015). Embedded contexts of innovation: BIM adoption and implementation for a specialty contracting SME. Construction Innovation, 15(1): 42-65

PTNB (2017). Barometer-BIM in the construction sector. PTNB (in French)

Rogers E M (2003). Diffusion of Innovations. 5th ed. New York: Simon and Schuster

Sainsaulieu R, Segrestin D (1986). Towards a sociological theory of business. Sociology of Labor, 28(3): 335-352 (in French)

Singh J V, House R J, Tucker D J (1986). Organizational change and organizational mortality. Administrative Science Quarterly, 31(4): 587-611

Smith P (2014). BIM Implementation-Global Strategies. Procedia Engineering, 85, 482-492

Stoneman P, Diederen P (1994). Technology diffusion and public policy. Economic Journal (London), 104(425): 918-930

Succar B (2009). Building information modelling framework: a research and delivery foundation for industry stakeholders. Automation in Construction , 18(3): 357-375

Succar B, Kassem M 2015. Macro-BIM adoption: conceptual structures. Automation in Construction, 57: 64-79

Tétard F, Collan M (2009). Lazy user theory: a dynamic model to understand user selection of products and services. In: 2009 42nd Hawaii International Conference on System Sciences, IEEE Conferences, 1-9

Turk $\breve{Z}$ (2000). Construction IT: definition, framework and research 
issues. In: Fischiner M, ed. Faculty of Civil and Geodetic Engineering on the Doorstep of the Millennium: On the Occasion of Its 80th Anniversary, 17-32

Venkatesh V, Davis F D (2000). A theoretical extension of the technology acceptance model: four longitudinal field studies. Management Science, 46(2): 186-204

Waarts E, van Everdingen Y M, van Hillegersberg J (2002). The dynamics of factors affecting the adoption of innovations. Journal of Product Innovation Management, 19(6): 412-423

Waterhouse R, Parkinson K, Malleson A (2017). National BIM Report 2017. NBS Report

Winch G, McDonald J (1999). SMEs in an environment of change: computer-based tools to aid learning and change management. Industrial and Commercial Training, 31(2): 49-56 